Article

\title{
Kinetic Investigation on Tetrakis(4- Sulfonatophenyl)Porphyrin J-Aggregates Formation Catalyzed by Cationic Metallo-Porphyrins
}

\author{
Ilaria Giuseppina Occhiuto ${ }^{1}$, Roberto Zagami ${ }^{2}$, Mariachiara Trapani ${ }^{2} \mathbb{D}$, \\ Maria Angela Castriciano ${ }^{2}\left(\mathbb{D}\right.$, Andrea Romeo ${ }^{1,2}$ (D) and Luigi Monsù Scolaro 1,2,*(D) \\ 1 Dipartimento di Scienze Chimiche, Biologiche, Farmaceutiche ed Ambientali, University of Messina and \\ C.I.R.C.M.S.B. V.le F. Stagno D'Alcontres, 31-98166 Messina, Italy; ilaria.occhiuto@gmail.com (I.G.O.); \\ anromeo@unime.it (A.R.) \\ 2 CNR-ISMN Istituto per lo Studio dei Materiali Nanostrutturati c/o Dipartimento di Scienze Chimiche, \\ Biologiche, Farmaceutiche ed Ambientali, University of Messina, V.le F. Stagno D'Alcontres, \\ 31-98166 Messina, Italy; roberto.zagami@ismn.cnr.it (R.Z.); mariachiara.trapani@cnr.it (M.T.); \\ maria.castriciano@cnr.it (M.A.C.) \\ * Correspondence: lmonsu@unime.it
}

Academic Editor: Alessandro D’Urso

Received: 18 November 2020; Accepted: 3 December 2020; Published: 5 December 2020

check for updates

\begin{abstract}
Under mild acidic conditions, various metal derivatives of tetrakis $(4-N$ methylpyridinium)porphyrin (gold(III), $\mathrm{AuT}_{4} ; \operatorname{cobalt}(\mathrm{III}), \mathrm{CoT}_{4} ;$ manganese(III), $\mathrm{MnT}_{4}$ and zinc(II), $\mathrm{ZnT}_{4}$ ) catalytically promote the supramolecular assembling process of the diacid 5,10,15,20tetrakis(4-sulfonatophenyl)porphyrin $\left(\mathrm{H}_{2} \mathrm{TPPS}_{4}\right)$ into J-aggregates. The aggregation kinetics have been treated according to a well-established model that involves the initial formation of a critical nucleus containing $m$ porphyrin units, followed by autocatalytic growth, in which the rate evolves as a power of time. An analysis of the extinction time traces allows to obtain the rate constants for the auto-catalyzed pathway, $k_{c}$, and the number of porphyrins involved in the initial seeding. The aggregation kinetics have been investigated at fixed $\mathrm{H}_{2} \mathrm{TPPS}_{4}$ concentration as a function of the added metal derivatives $\mathrm{MT}_{4}$. The derived rate constants, $k_{c}$, obey a rate law that is first order in $\left[\mathrm{MT}_{4}\right]$ and depend on the specific nature of the catalyst in the order $\mathrm{AuT}_{4}>\mathrm{CoT}_{4}>\mathrm{MnT}_{4}>\mathrm{ZnT}_{4}$. Both resonance light scattering (RLS) intensity and extinction in the aggregated samples increase on increasing $\left[\mathrm{MT}_{4}\right]$. With the exception of $\mathrm{AuT}_{4}$, the final aggregated samples obtained at the highest catalyst concentration exhibit a negative Cotton effect in the J-band region, evidencing the occurrence of spontaneous symmetry breaking. The role of the nature of the metal derivative in terms of overall charge and presence of axial groups will be discussed.
\end{abstract}

Keywords: J-aggregates; aggregation kinetics; chiral supramolecular assemblies; symmetry breaking

\section{Introduction}

Spontaneous self-assembling of molecular units into ordered and larger stable arrangements through non-covalent interactions is a topic that in the last few years has received significant attention from the research community due to its large impact on many aspects of chemistry [1,2]. Porphyrins certainly represent a class of compounds that are extremely interesting in this regard because, depending on both their electronic and steric characteristics, they are susceptible to aggregation forming dimers and/or larger molecular oligomers [3-6]. In this respect, water-soluble porphyrins are excellent candidates to explore the aggregation process, which can be suitably modulated by varying the medium properties, such as $\mathrm{pH}$ and ionic strength, or by taking advantage of the coordination chemistry properties of the central macrocycle. The latter may be indeed readily metallated with 
a wide variety of metal ions, thereby giving access to peculiar photophysical and photochemical properties [7-10]. However, despite many reports on the formation of porphyrin homo-aggregates, there are relatively few literature investigations on hetero-aggregated systems. Self-assembly between cationic and anionic meso-substituted porphyrins, mainly driven by electrostatic attraction of peripheral substituent groups, hydrophobic interactions and axial coordination, represents an easy way to design hetero-aggregated supramolecular species [11-17], even if the formation of discrete hetero-dimers has been reported only in water/organic solvents mixtures $[18,19]$. In this context, the targeted use of anionic porphyrins such as 5,10,15,20-tetrakis(4-sulfonatophenyl) porphyrin $\mathrm{TPPS}_{4}$, whose diacid form is able to give both J- (edge-to-edge) and H-type (face-to-face) self-aggregates, is particularly attractive since these structures exhibit peculiar emergent photophysical properties tunable through aggregate topology and molecular arrangement [20-30]. In the literature, some examples concerning the use of $\mathrm{TPPS}_{4}$ in the formation of hetero-aggregated systems have been reported [31-37] and, among them, some focus on the possibilities of using $\mathrm{TPPS}_{4}$ in applicative fields. Shelnutt et al. [35] described the formation of nanotubular J-aggregates whose structure retains own individual porphyrin properties as photocatalytic reduction of metals, while Oztek et al. reported on the potential use of hetero-aggregates as hydrogen storage materials [36].

Other relevant examples in the field involve the additional use of suitable chiral templating units aimed to obtain aggregates exhibiting a well-defined stoichiometric ratio that are able to memorize and amplify the chiral information [33,34,38-41]. Despite the many reports on thermodynamic and spectroscopic characterization of these supramolecular species, kinetic studies are rather scarce due to the difficulty in controlling the various parameters that influence the aggregation pathways and eventually the final structures at the nano- or mesoscale [42,43]. Notwithstanding, the knowledge of the kinetic behavior is a prerequisite to understanding the factors controlling the rate determining step and the early stages in these complex phenomena. On the basis of our previous spectroscopic investigations on the formation of hetero-oligomers and the subsequent J-aggregates induction [31], here, we describe a detailed kinetic study on the role of cationic metallo-porphyrins $\mathrm{MT}_{4}$ in the supramolecular assembling process leading to J-aggregates of TPPS 4 (Scheme 1). Both $\mathrm{MT}_{4}$ and TPPS porphyrins do not show any tendency towards self-aggregation in the adopted experimental conditions and we anticipate that: (i) the addition of $\mathrm{MT}_{4}$ to solutions of $\mathrm{TPPS}_{4}$ easily promotes J-aggregation, even under mild acidic conditions; (ii) the kinetic rates and the extent of aggregation depend linearly on the cationic porphyrin concentration and on the overall characteristics of these metal derivatives (charge and axial substituent groups), following the order $\mathrm{AuT}_{4}>\mathrm{CoT}_{4}>\mathrm{MnT}_{4}>\mathrm{ZnT}_{4}$; (iii) in most cases, the number of porphyrins in the critical nucleus is slightly less than 3-4, as previously reported for the uncatalyzed process; and iv) except for the most effective metal derivative ( $\left.\mathrm{AuT}_{4}\right)$, small CD spectra are always detectable, thus adding to the growing number of examples of spontaneous symmetry breaking in J-aggregates [44-48].

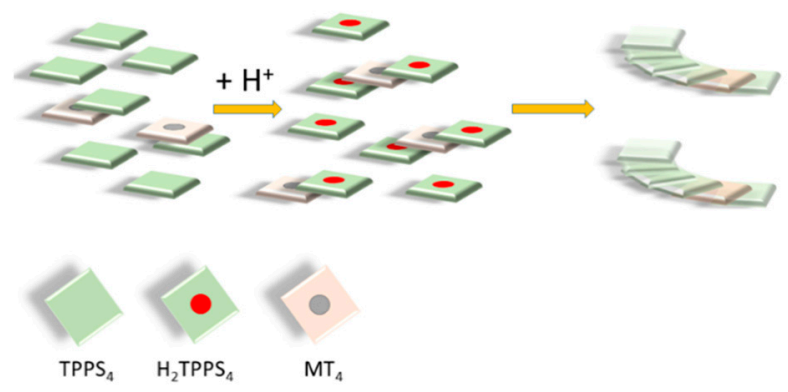

Scheme 1. Pictorial sketch of $\mathrm{TPPS}_{4}$ protonation and subsequent J-aggregation in the presence of cationic metallo-porphyrins $\mathrm{MT}_{4}$. 


\section{Results and Discussion}

At neutral or alkaline $\mathrm{pH}$, aqueous solutions of the parent free-base porphyrin at micro-molar concentration stabilize toward self-aggregation. The nitrogen atoms at the core of the tetra-anionic porphyrin $\mathrm{TPPS}_{4}$ are protonated $(\mathrm{pKa}=4.9$ [49]) and this species is fully converted to its diacid dianionic form $\mathrm{H}_{2}$ TPPS $_{4}$ at pH 2.8 (B-band at $434 \mathrm{~nm}$, see black line in Figure 1). In the presence of only $\mathrm{HCl}$ at this $\mathrm{pH}$, the formation of J-aggregates of $\mathrm{H}_{2} \mathrm{TPPS}_{4}$ is kinetically very slow and a tiny concentration can be detected after at least $24 \mathrm{~h}$. In order to investigate the catalytic role of the various metal derivatives of the cationic tetrakis(4- $N$-methylpyridinium)porphyrin $\left(\mathrm{MT}_{4}\right)$, these latter species have been pre-incubated at different molar ratios $\mathrm{R}$ with $\mathrm{TPPS}_{4}$ in water $\left(\mathrm{R}=\left[\mathrm{TPPS}_{4}\right] /\left[\mathrm{MT}_{4}\right]\right.$, with $\mathrm{R}$ spanning in the range $2 \div 30$ ) and then aggregation has been triggered by lowering the $\mathrm{pH}$ to 2.8 through addition of $\mathrm{HCl}$. All the investigated $\mathrm{MT}_{4}$ derivatives form hetero-aggregates with the anionic $\mathrm{TPPS}_{4}$ and their spectroscopic features and stoichiometry have been reported in literature [31]. Figure 1 displays the typical time evolution of the UV/Vis spectra observed for both $\mathrm{CoT}_{4}$ (Figure 1, left) and $\mathrm{AuT}_{4}$ (Figure 1, right) at the highest ratio $\mathrm{R}=2$. The gold(III) metal complex interacting with $\mathrm{H}_{2} \mathrm{TPPS}_{4}$ exhibits an initial B-band at $405 \mathrm{~nm}$ that decreases in intensity and undergoes a further bathochromic shift to $411 \mathrm{~nm}$, matched by the decrease of the B- and Q-bands of the diacid $\mathrm{H}_{2} \mathrm{TPPS}_{4}$ at 434 and $644 \mathrm{~nm}$, respectively, and the concomitant increase of the J-aggregate B-band at $491 \mathrm{~nm}$, together with its Q-band at $704 \mathrm{~nm}$. $\mathrm{MnT}_{4}$ display a B-band at $462 \mathrm{~nm}$ and it undergoes a bathochromic shift of $6 \mathrm{~nm}$ upon aggregation (see Supporting Information, Figure S7). In the case of $\mathrm{CoT}_{4}$, the B-band of this species $(434 \mathrm{~nm})$ is under the envelope of the diacid $\mathrm{H}_{2} \mathrm{TPPS}_{4}$ and consequently, not detectable. $\mathrm{ZnT}_{4}$ exhibits a B-band at $436 \mathrm{~nm}$ and follows the same pattern of $\mathrm{CoT}_{4}$. Upon addition of $\mathrm{HCl}$, a decrease of the B-band of the diacid species also occurs, while the J-band at $490 \mathrm{~nm}$ increases in intensity.
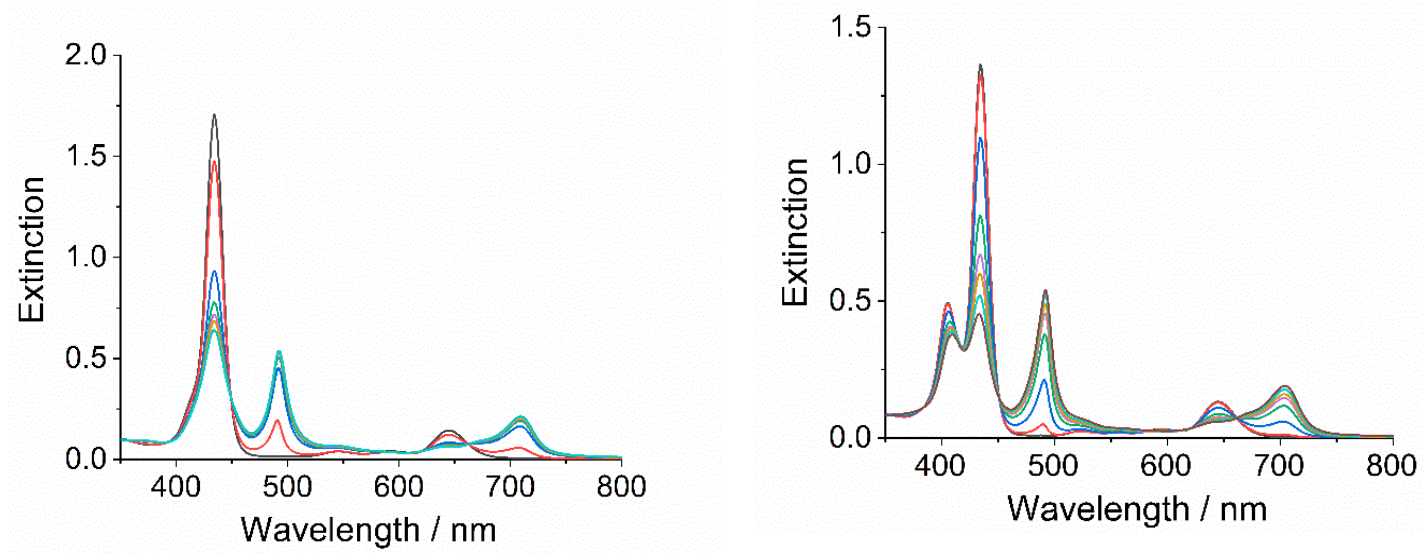

Figure 1. UV/Vis extinction spectral changes for the aggregation of $\mathrm{TPPS}_{4}$ into J-aggregates in the presence of $\mathrm{CoT}_{4}$ (left) and $\mathrm{AuT}_{4}$ (right) after the addition of hydrochloric acid. For $\mathrm{CoT}_{4}: 0$ (black), 40 (red), 80 (blue), 120 (green), 160 (violet), 210 (yellow), 340 s (cyano); For AuT 4 : 0 (black), 10 (red), 20 (blue), 30 (green), 40 (violet), 50 (yellow), 80 (cyano), $220 \mathrm{~s}$ (brown). (Experimental conditions: $\left[\mathrm{TPPS}_{4}\right]=3 \mu \mathrm{M} ;\left[\mathrm{MT}_{4}\right]=1.5 \mu \mathrm{M} ;[\mathrm{HCl}]=0.00158 \mathrm{M}, \mathrm{T}=298 \mathrm{~K}$, total acquisition time $\left.400 \mathrm{~s}\right)$.

The kinetics of growth of J-aggregates can be easily followed by monitoring the extinction of the samples at $490 \mathrm{~nm}$. Figure 2 shows a typical kinetic profile for the aggregation induced by $\mathrm{CoT}_{4}$. As already reported for acid-induced aggregation of $\mathrm{H}_{2} \mathrm{TPPS}_{4}$, a sigmoidal behavior is clearly observed with a quite short initial incubation or lag-time followed by an exponential growth. These data have been treated by a well-established autocatalytic model, in which two independent pathways are operative: (i) an uncatalyzed one, controlled by a rate $\mathrm{k}_{0}$ and (ii) a catalyzed one, dominated by a stretched exponential form with $k_{c}$ as the rate constant and $\mathrm{n}$ as the time exponent. The rate determining step of the second pathway is the initial formation of a nucleus containing $\mathrm{m}$ monomeric porphyrin units [50,51]. All the kinetic parameters have been obtained by a non-linear best-fitting procedure that 
was applied to the experimental extinction data and collected in Table S1 (see Supporting Information), with the exception of $\mathrm{k}_{0}$, which makes no or only a minor contribution to the overall fit of the data.

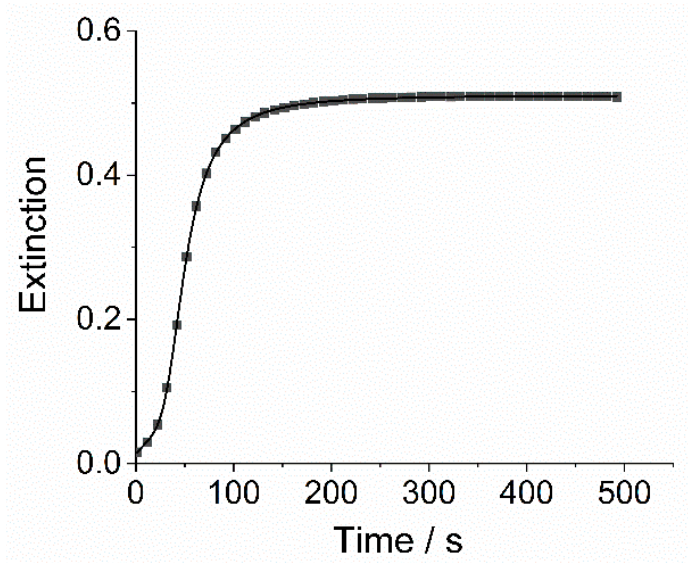

Figure 2. Typical kinetic profile of extinction at $491 \mathrm{~nm}$ vs. time for the aggregation of $\mathrm{TPPS}_{4}$ catalyzed by $\mathrm{CoT}_{4}$. The black line is the best fit of the experimental data to Equation (1) (Experimental conditions: $\left.\left[\mathrm{TPPS}_{4}\right]=3 \mu \mathrm{M} ;\left[\mathrm{CoT}_{4}\right]=1.5 \mu \mathrm{M} ;[\mathrm{HCl}]=0.00158 \mathrm{M}, \mathrm{T}=298 \mathrm{~K}\right)$.

As an example, Figure 3 (left) displays the typical linear dependence of the values of the rate constant $k_{c}$ as a function of the increasing concentration of [ $\left.\mathrm{CoT}_{4}\right]$. The related values for the time exponent $n$ range between 3 and 4 , while the size of the initial nucleus $m \approx 2-3$ (dimer or trimer) is slightly lower with respect to what is reported in the literature for acid-induced aggregation of the parent porphyrin. In these latter cases, $m$ values suggested the involvement of a trimer or a tetramer in the rate determining step [47,52-54]. This difference could be ascribed to the different nature of the starting building block for the aggregation process, where a heterodimer stabilized by electrostatic interactions could be responsible for the seeding of the growth. As already reported in the literature [31], the cationic porphyrins investigated here form such kinds of supramolecular species with variable stoichiometry. This observation, together with a certain degree of variation on $\mathrm{m}$ values measured for $\mathrm{ZnT}_{4}$ and $\mathrm{AuT}_{4}$ (see Table S1), suggests the potential formation of concentration dependent hetero-oligomers as initiators for the catalytic growth of the $\mathrm{H}_{2} \mathrm{TPPS}_{4} \mathrm{~J}$-aggregates.
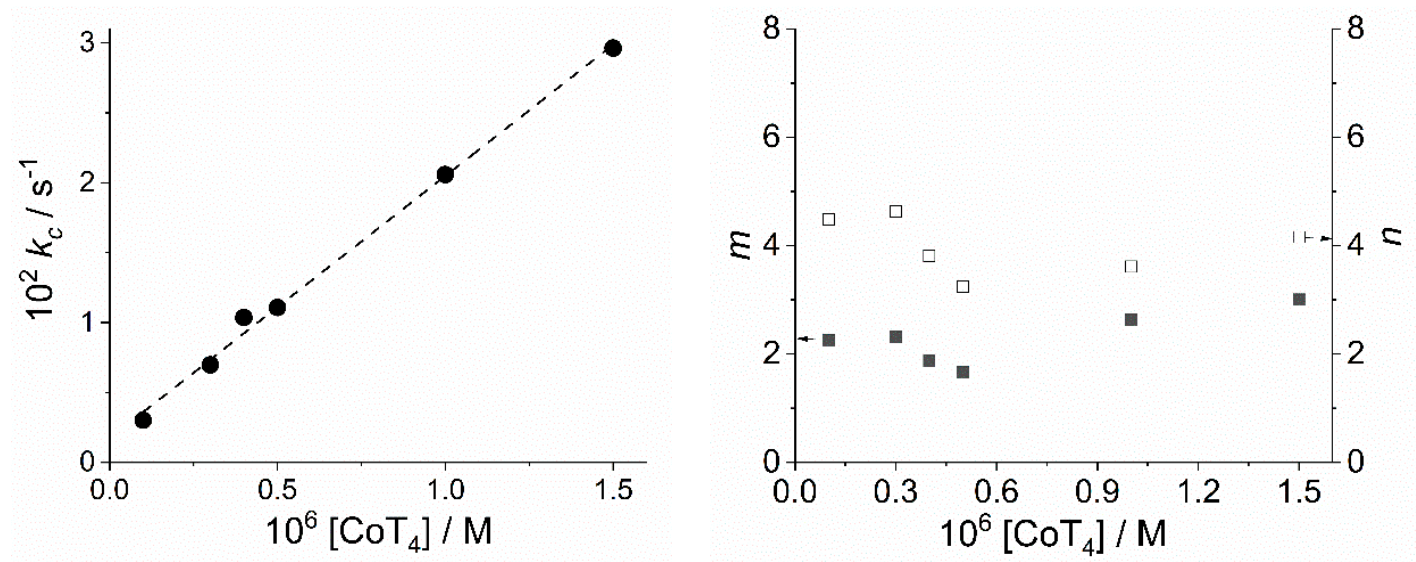

Figure 3. Plot of the autocatalytic rate constants $k_{c}\left(\mathrm{~s}^{-1}\right)(\mathbf{l e f t})$, the line represents the linear fit of the experimental data to the equation $k_{c}=\left(1.7 \times 10^{-3} \pm 5 \times 10^{-4}\right)+\left(1.88 \times 10^{-2} \pm 6 \times 10^{-4}\right) \times\left[\mathrm{CoT}_{4}\right]$, and the values of $\mathrm{m}$ (full squares) and $\mathrm{n}$ (empty squares) for the aggregation of $\mathrm{TPPS}_{4}$ as a function of $\left[\mathrm{CoT}_{4}\right]$ (right). (Experimental conditions: $\left.\left[\mathrm{TPPS}_{4}\right]=3 \mu \mathrm{M} ;[\mathrm{HCl}]=0.00158 \mathrm{M}, \mathrm{T}=298 \mathrm{~K}\right)$.

Resonance light scattering from aggregated samples confirms the presence of quite large arrays of electronically coupled porphyrin units $(\mathrm{N}>25)$ [55]. The intensity of a resonance light scattering 
(RLS) peak depends on the scattering and the absorption cross-sections of the aggregates and therefore on their size and concentration [56]. Figure 4 shows the RLS spectra of aggregated samples for the case of the $\mathrm{CoT}_{4}$ catalyzed process. The intensities of the peaks centered at about $490 \mathrm{~nm}$ increase on increasing $\left[\mathrm{CoT}_{4}\right]$.

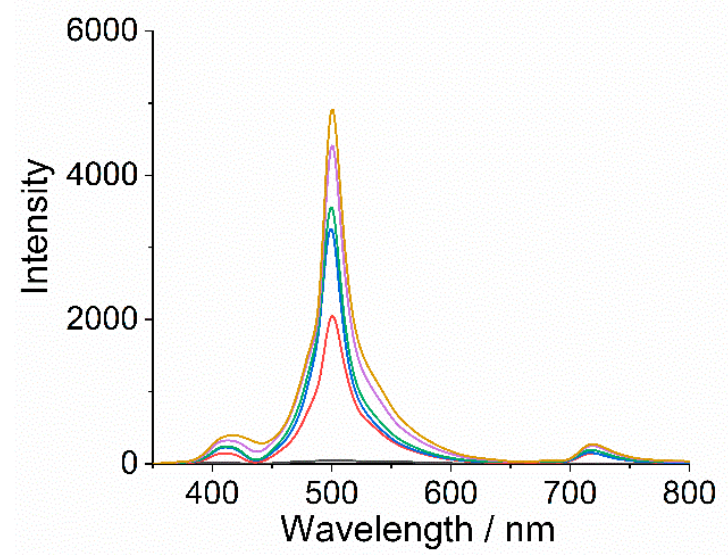

Figure 4. Resonance light scattering (RLS) spectra of the samples at the end of the aggregation process catalyzed by $\mathrm{CoT}_{4}$ at different concentrations of this metal derivative. (Experimental conditions: $\left[\mathrm{TPPS}_{4}\right]=3 \mu \mathrm{M} ;[\mathrm{HCl}]=0.00158 \mathrm{M},\left[\mathrm{CoT}_{4}\right]=0.1 \mu \mathrm{M}$ (black), $0.3 \mu \mathrm{M}$ (red), $0.4 \mu \mathrm{M}$ (blue), $0.5 \mu \mathrm{M}$ (green), $1 \mu \mathrm{M}$ (violet), $1.5 \mu \mathrm{M}$ (yellow), $\mathrm{T}=298 \mathrm{~K}$ ).

Analogously, both the intensity of RLS corrected for the extinction of the solutions and the extinction increase linearly on increasing [CoT 4 (Figure 5), in line with an increment in size and concentration of the formed aggregates. Since the enhancement of the scattered light at resonance with the absorption feature reflects the strong electronic coupling among the porphyrins and increases with their numbers in the aggregate [55], this evidence points to a progressive stabilization of the nano-assemblies mediated by the cationic porphyrins.
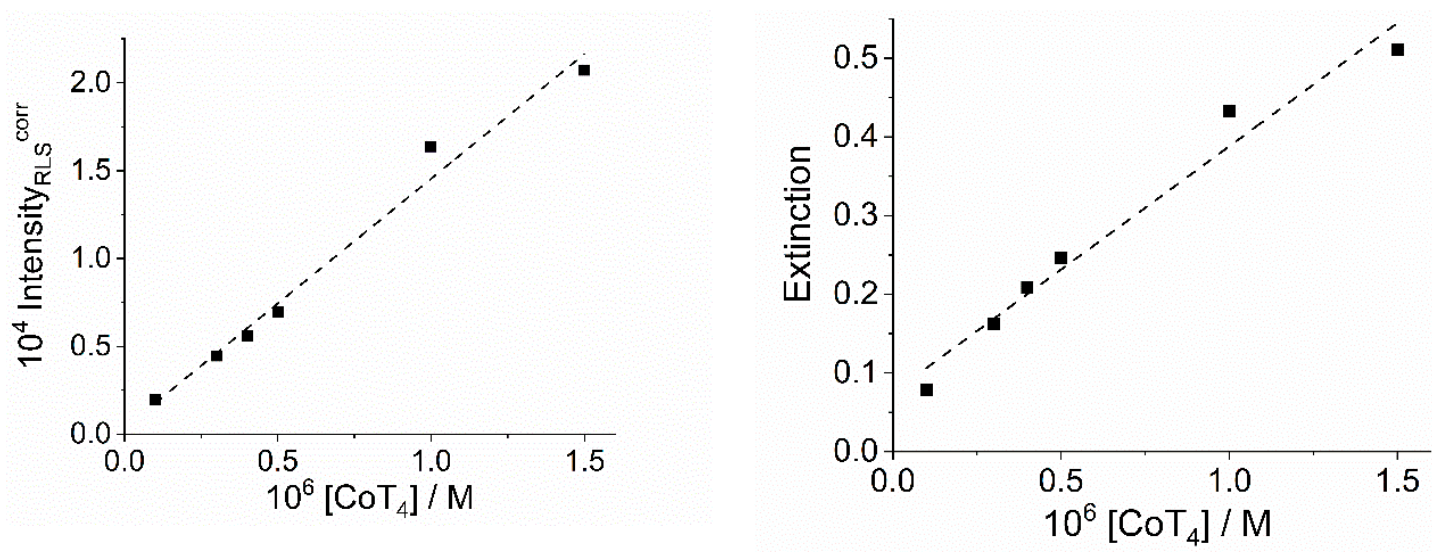

Figure 5. Intensity of RLS spectra corrected for extinction (left) and extinction of the samples at the end of the $\mathrm{TPPS}_{4}$ aggregation process catalyzed by $\mathrm{CoT}_{4}$ (right) as a function of the concentration of this metal derivative. (Experimental conditions: $\left[\mathrm{TPPS}_{4}\right]=3 \mu \mathrm{M} ;[\mathrm{HCl}]=0.00158 \mathrm{M}, \mathrm{T}=298 \mathrm{~K}$ ). The lines represent the linear best fits to the experimental data $\left(\mathrm{I}_{\mathrm{RLS}}{ }^{\mathrm{corr}}=10^{4} \times(0.035 \pm 0.074)+10^{4} \times\right.$ $\left.(1.419 \pm 0.093) \times\left[\mathrm{CoT}_{4}\right] ; \mathrm{Ext}=(0.075 \pm 0.022)+(0.313 \pm 0.028) \times\left[\mathrm{CoT}_{4}\right]\right)$.

Interestingly, the intensity of RLS increases on increasing the aggregation rate constant $k_{c}$ (Figure 6). The data have been analyzed through a linear best fitting, obtaining $\mathrm{I}_{\mathrm{RLS}}{ }^{\mathrm{corr}}=(-912 \pm 905)+10^{5} \times$ $(7.53 \pm 0.56) \times k_{c}$. On one hand, this behavior is in contrast with that observed for the acid-induced aggregation of $\mathrm{TPPS}_{4}$, where an inverse dependence has been reported for the growth of porphyrin nanotubes [47]. On the other hand, when these nanoassemblies are formed in the presence of a 
high concentration of $\mathrm{Zn}^{2+}$, again a linear dependence between these two parameters has been reported [52]. These findings suggest that the structural arrangement of the chromophores in these specific supramolecular species are quite different with respect to that involved in nanotubes. Further evidence for a difference in the aggregate architecture stems from the slight broadening of the J-band for all the final aggregated samples. These spectral features appear generally larger than those reported for systems where the Frenkel exciton model for the electronic coupling among chromophores is operative [57].

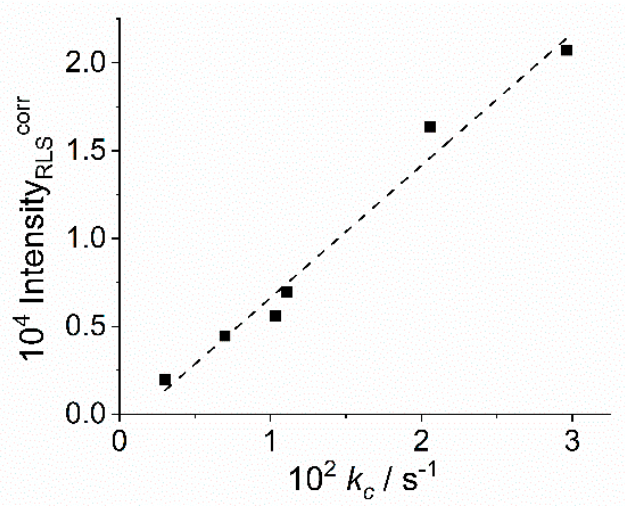

Figure 6. Plot of the RLS intensity at maxima corrected for the extinction of the samples as a function of the corresponding rate constants $k_{c}$ for the J-aggregation catalyzed by $\mathrm{CoT}_{4}$. (Experimental conditions: $\left.\left[\mathrm{TPPS}_{4}\right]=3 \mu \mathrm{M} ;\left[\mathrm{CoT}_{4}\right]=1.5 \mu \mathrm{M} ;[\mathrm{HCl}]=0.00158 \mathrm{M}, \mathrm{T}=298 \mathrm{~K}\right)$. The line represents the linear best fit to the experimental data $\left(\mathrm{I}_{\mathrm{RLS}}{ }^{\mathrm{corr}}=10^{5} \times(-0.009 \pm 0.009)+10^{5}(7.531 \pm 0.556) \times k_{c}\right)$.

When comparing the values of $k_{c}$ for the various metal derivatives, a monotonic increase is well evident together with a different efficiency in promoting the aggregation of TPPS $_{4}$. Figure 7 reports the behavior of $k_{c}$ as a function of increasing $\left[\mathrm{MT}_{4}\right]$ for the investigated cationic porphyrins. All the data have been best-fitted to the equation $k_{c}=k_{M T 4}^{\prime} \times\left[\mathrm{MT}_{4}\right]$ and the values of the relative slope $k_{M T 4}^{\prime}$ follow the trend: $\mathrm{AuT}_{4}>\mathrm{CoT}_{4}>\mathrm{MnT}_{4}>\mathrm{ZnT}_{4}$ (Figure 8, left). The ability of the various porphyrins in accelerating the formation of J-aggregates is paralleled by their attitude in stabilizing larger aggregates or higher concentrations, as shown in Figure 8 (right), where the values of $\mathrm{I}_{\mathrm{RLS}}{ }^{\mathrm{corr}}$ and extinction for fully aggregated samples at the highest investigated concentration are displayed.

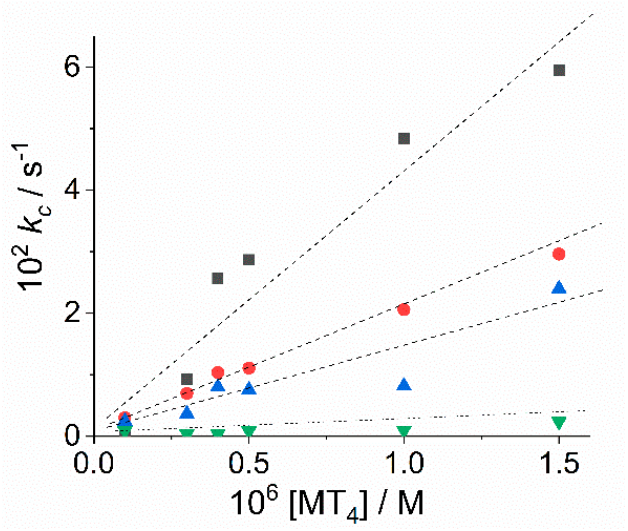

Figure 7. Plot of the autocatalytic rate constants $k_{c}\left(\mathrm{~s}^{-1}\right)$ for the aggregation of $\mathrm{TPPS}_{4}$ as a function of $\left[\mathrm{MT}_{4}\right]$ for the various metal derivatives. $\mathrm{AuT}_{4}$ (black squares), $\mathrm{CoT}_{4}$ (red circles), $\mathrm{MnT}_{4}$ (blue triangles), $\mathrm{ZnT}_{4}$ (green triangles). (Experimental conditions: [TPPS $\left.{ }_{4}\right]=3 \mu \mathrm{M} ;[\mathrm{HCl}]=0.00158 \mathrm{M}, \mathrm{T}=298 \mathrm{~K}$ ). The straight lines represent the linear fit to the rate data, according to the equation $k_{c}=k_{M T 4}^{\prime} \times\left[\mathrm{MT}_{4}\right]$. 

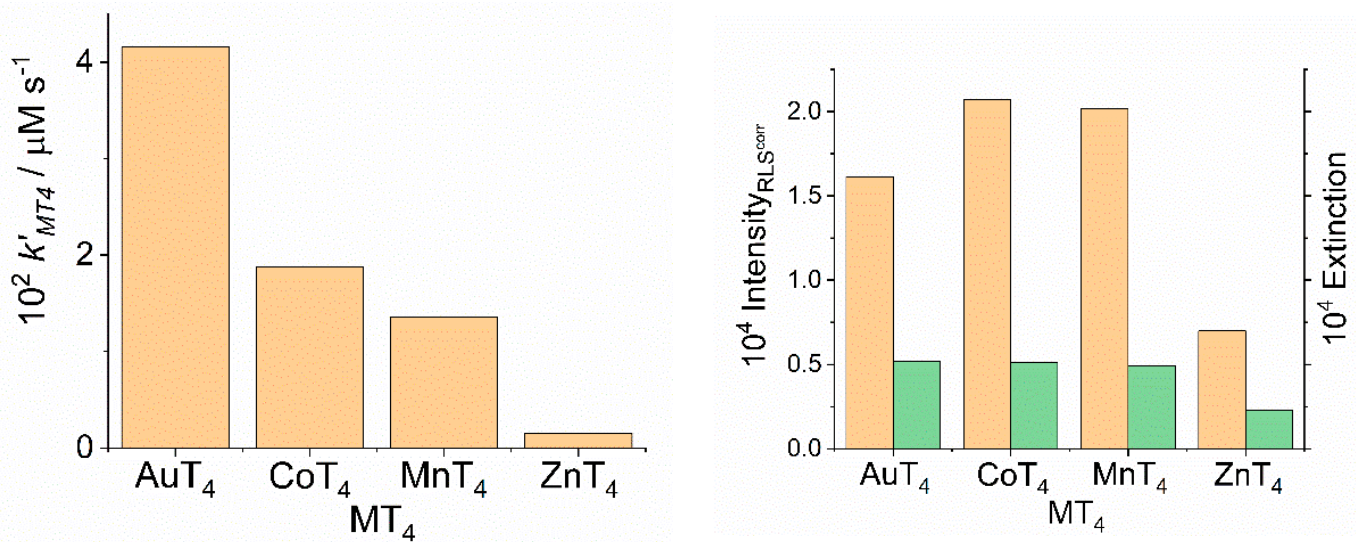

Figure 8. Bar plot of the rate constants $k_{M T 4}^{\prime}\left(\mu \mathrm{M} \times \mathrm{s}^{-1}\right)$ obtained as slope from Figure 7 (left) and the RLS intensity at maxima corrected for the extinction (orange bars) and extinction (green bars) of the samples after complete aggregation of $\mathrm{TPPS}_{4}$ for the various metal derivatives $\mathrm{MT}_{4}$ (right). (Experimental conditions: $\left[\mathrm{TPPS}_{4}\right]=3 \mu \mathrm{M} ;\left[\mathrm{MT}_{4}\right]=1.5 \mu \mathrm{M} ;[\mathrm{HCl}]=0.00158 \mathrm{M}, \mathrm{T}=298 \mathrm{~K}$ ).

An intriguing property of $\mathrm{TPPS}_{4} \mathrm{~J}$-aggregates is their propensity to spontaneous symmetry breaking, leading to an unbalance in the mixture of enantiomorphous nanostructures. This occurrence can be detected through circular dichroism spectroscopy and these supramolecular assemblies exhibit exciton coupled CD spectra at the wavelength of their absorption bands. In the case of J-aggregates formed in the presence of inorganic acids, the intensity of the usually observed positive Cotton effect can be quite large and an inverse dependence on the aggregation rate has been reported [46,47]. In the present case, very weak negative exciton split CD spectra are detectable at the J-band for all the samples obtained in the presence of the cationic porphyrins, with the exception of $\mathrm{AuT}_{4}$ (Figure 9). This evidence supports the hypothesis that the presence of $\mathrm{MT}_{4}$ species promotes structurally different aggregates with respect to nanotubes.

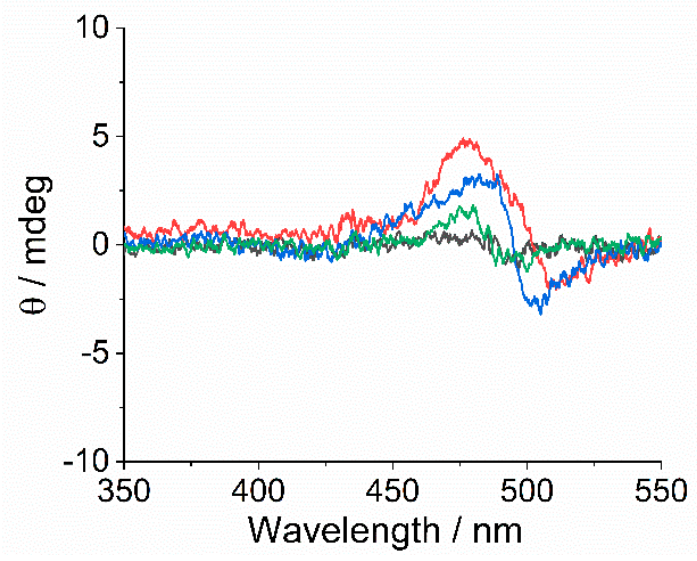

Figure 9. CD spectra of the samples after complete aggregation of $\mathrm{TPPS}_{4}$ for the various metal derivatives $\mathrm{MT}_{4}\left(\mathrm{AuT}_{4}\right.$ (black), $\mathrm{CoT}_{4}$ (red), $\mathrm{MnT}_{4}$ (blue), $\mathrm{ZnT}_{4}$ (green). (Experimental conditions: $\left.\left[\mathrm{TPPS}_{4}\right]=3 \mu \mathrm{M} ;\left[\mathrm{MT}_{4}\right]=1.5 \mu \mathrm{M} ;[\mathrm{HCl}]=0.00158 \mathrm{M}, \mathrm{T}=298 \mathrm{~K}\right)$.

On the basis of the collected evidence, a mechanistic pathway to aggregation can be proposed (Scheme 2). In water at neutral $\mathrm{pH}$, the TPPS 4 porphyrin is not protonated and therefore it is a tetra-anion able to strongly interact with cationic $\mathrm{MT}_{4}$ metallo-porphyrins, leading to different hetero-aggregates $\left(\mathrm{MT}_{4} @ \mathrm{TPPS}_{4}\right)$. These latter species possess an overall charge that depends on the coordinated metal ion $(\mathrm{Au}(\mathrm{III})+5 ; \mathrm{Co}(\mathrm{III})+5 ; \mathrm{Mn}(\mathrm{III})+5 ; \mathrm{Zn}(\mathrm{II})+4)$ in the cationic species. Further, the nature of the metal ion imposes different coordination numbers and geometries: (i) $\mathrm{Au}$ (III) 4-coordinated and square planar; (ii) $\mathrm{Co}$ (III) and $\mathrm{Mn}$ (III) 6-coordinated and octahedral; and (iii) $\mathrm{Zn}$ (II) 5-coordinated 
and square pyramidal. The resulting different charge and geometrical structures of the various metal complexes have an impact on the stoichiometry and interaction among porphyrins in the formation of the hetero-aggregated species. Moreover, upon lowering the $\mathrm{pH}$ to 2.8 , the $\mathrm{TPPS}_{4}$ porphyrin is further protonated at the macrocyclic core and its overall charge decreases to -2 in the diacid $\mathrm{H}_{2} \mathrm{TPPS}_{4}$. This event determines a rearrangement of the hetero-aggregates $\left(\mathrm{MT}_{4} @ \mathrm{H}_{2} \mathrm{TPPS}_{4}\right)$ and their stoichiometry were reported as ranging from 1:3 to 2:3 for the $\mathrm{AuT}_{4} @ \mathrm{H}_{2} \mathrm{TPPS}_{4}$ species and 2:3 for $\mathrm{MnT}_{4} @ \mathrm{H}_{2} \mathrm{TPPS}_{4}$ and $\mathrm{ZnT}_{4} @ \mathrm{H}_{2} \mathrm{TPPS}_{4}$ [31]. The preference for an edge-to-edge interaction (J-type) in these hetero-oligomers was explained (i) in terms of a steric role of the axial substituent groups, as in the penta- $\left(\mathrm{ZnT}_{4}\right)$ and hexa-coordinated $\left(\mathrm{CoT}_{4}\right.$ and $\left.\mathrm{MnT}_{4}\right)$ complexes, thus preventing a potential face-to-face contact (H-type) and (ii) the net positive charge at the core of the macrocycle $\left(\mathrm{AuT}_{4}\right)$, leading to a repulsive interaction with the diprotonated $\mathrm{H}_{2} \mathrm{TPPS}_{4}$. All these factors determine the observed trend in the efficiency of the $\mathrm{MT}_{4}$ species to influence both the rates and the eventual extent of aggregation. Indeed, these J-hetero-oligomers can be considered as the real initiators of the assembling process. Alternatively, the further addition of $\mathrm{H}_{2} \mathrm{TPPS}_{4}$ monomers determines the formation of the critical nucleus $\left(\mathrm{MT}_{4} @\left(\mathrm{H}_{2} \mathrm{TPPS}_{4}\right)_{\mathrm{m}}\right)$. From this point on, the autocatalytic pathway controlled by the rate constants $k_{c}$ leads to the growth of the final J-aggregates. It is interesting to observe that, when detectable, the final position of the B-band related to the $\mathrm{MT}_{4}$ species in the UV/Vis spectra suggests their involvement into the nano-assemblies (Figure S7). In addition, slight bathochromic shifts can be measured in the B-and Q-bands of the final J-aggregates (AuT 4 ,492/704 nm; $\mathrm{CoT}_{4}, 492 / 709$ nm; $\mathrm{MnT}_{4} 493 / 709 \mathrm{~nm} ; \mathrm{ZnT}_{4}, 496 / 712 \mathrm{~nm}$ ), supporting the hypothesis of a substantial incorporation of the cationic metallo-porphyrins in the J-aggregates. This evidence is in line with literature data showing the incorporation of $\mathrm{Sn}(\mathrm{IV})$ cationic species into nanotubes of $\mathrm{H}_{2} \mathrm{TPPS}_{4}$ [35].

$$
\mathrm{MT}_{4} @ \mathrm{TPPS}_{4} \stackrel{+\mathrm{H}^{+}}{\rightleftarrows} \mathrm{MT}_{4} @ \mathrm{H}_{2} \mathrm{TPPS}_{4} \stackrel{+\mathrm{H}_{2} \mathrm{TPPS}_{4}}{\longrightarrow} \mathrm{MT}_{4} @\left(\mathrm{H}_{2} \mathrm{TPPS}_{4}\right)_{\mathrm{m}} \longrightarrow \text { J-Aggregates }
$$

Scheme 2. Proposed mechanism for J-aggregation of $\mathrm{TPPS}_{4}$ in the presence of cationic metalloporphyrins $\mathrm{MT}_{4}$ under mild acidic conditions.

\section{Materials and Methods}

Materials. 5, 10, 15, 20-tetrakis(4-sulfonatophenyl)porphine (TPPS 4 ) was purchased from Aldrich Chemical Co. Au(III), Mn(III), Co(III), Zn(II) derivatives of tetrakis(4-N-methylpyridyl)porphine $\left(\mathrm{H}_{2} \mathrm{~T}_{4}\right)$ were prepared according to literature procedures [7-10]. These porphyrins were solubilized in high-purity doubly distilled water from Galenica Senese. The range of concentration used in our experiments was determined spectrophotometrically using the molar extinction coefficients at the Soret maxima $\left(\mathrm{TPPS}_{4}: 5.33 \times 10^{5} \mathrm{M}^{-1} \mathrm{~cm}^{-1}, \lambda=414 \mathrm{~nm} ; \mathrm{AuT}_{4}: 2.82 \times 10^{5} \mathrm{M}^{-1} \mathrm{~cm}^{-1}, \lambda=403 \mathrm{~nm} ; \mathrm{MnT}_{4}\right.$ : $1.29 \times 10^{5} \mathrm{M}^{-1} \mathrm{~cm}^{-1}, \lambda=462 \mathrm{~nm} ; \mathrm{CoT}_{4}: 1.68 \times 10^{5} \mathrm{M}^{-1} \mathrm{~cm}^{-1}, \lambda=434 \mathrm{~nm} ; \mathrm{ZnT}_{4}: 1.81 \times 10^{5} \mathrm{M}^{-1} \mathrm{~cm}^{-1}$, $\lambda=436 \mathrm{~nm})$.

Methods. UV/Vis absorption spectra and kinetic traces were measured on an Agilent model HP 8453 diode array spectrophotometer. An UV filter (Hoya glass type UV-34, cut-off: 340 nm) was used in the kinetic measurements in order to cut off the UV component of the spectrophotometer lamp, preventing the photodegradation of porphyrins. Resonance light scattering (RLS) experiments were performed on a Jasco mod. FP-750 spectrofluorimeter, adopting a synchronous scan protocol with a right angle geometry [56]. Circular dichroism experiments were carried out on a Jasco mod. J-710 spectropolarimeter. Aggregation occurs by addition of a known volume of a concentrated stock solution of hydrochloric acid (final concentration $[\mathrm{HCl}]=1.58 \mathrm{mM}, \mathrm{pH}=2.8$ ) to a solution of porphyrin $(3 \mu \mathrm{M})$ premixed with a solution of metal cationic porphyrins (final concentration $\left[\mathrm{MT}_{4}\right]=0.1,0.3,0.4$, $0.5,1,1.5 \mu \mathrm{M})$. Kinetic experiments were run by acquiring extinction spectra from the mixed solutions placed in the thermostatic sample holder of the spectrophotometer ( $298 \mathrm{~K})$. The aggregation kinetics exhibit a sigmoidal profile that can be fitted by an autocatalytic model $[47,50,51]$. The extinction traces collected at $490 \mathrm{~nm}$ were analyzed by a non-linear least square fit to the equation: 


$$
\operatorname{Ext}_{\mathrm{t}}=\operatorname{Ext}_{\infty}+\left(\operatorname{Ext}_{0}-\operatorname{Ext}_{\infty}\right)\left(1+(m-1)\left\{k_{0} \mathrm{t}+(n+1)^{-1}\left(k_{c} \mathrm{t}\right)^{n+1}\right\}\right)^{-1 /(m-1)}
$$

where $\operatorname{Ext}_{0}, \operatorname{Ext}_{\infty}, k_{0}, k_{c}, \mathrm{~m}$, and $\mathrm{n}$ are the optimized parameters.

\section{Conclusions}

Kinetic investigations offer the opportunity to gain insights on how the growth of supramolecular assemblies is controlled by specific changes of the medium and other external factors. The J-aggregates formed by the water sulfonated porphyrin $\mathrm{TPPS}_{4}$ have been highly investigated for their ability to self-assemble into a variety of nano- and mesoscopic supramolecular structures. The specific arrangement and electronic coupling of the chromophores inside these species control their spectroscopic features and properties, such as their chirality. Understanding the role of other chemical components able to mediate, catalyze, and eventually to be incorporated into the final aggregates is therefore very important. The present study adds another small piece of information on these systems. Here, we demonstrated that $\mathrm{MT}_{4}$ porphyrins are effective in accelerating the J-aggregation of $\mathrm{H}_{2} \mathrm{TPPS}_{4}$ and that their efficiency is strongly dependent on their electronic and steric characteristics. Cationic metallo-porphyrins enter as part of the nano-architecture and the presence of transition metal ions could potentially introduce novel properties, such as catalytic activity.

Supplementary Materials: The following are available online. Figure S1: Autocatalytic rate constants $k_{c}$ and the values of $m$ and $n$ for the aggregation of $\mathrm{TPPS}_{4}$ vs. [AuT 4 ], Figure S2: RLS intensity and extinction vs. [AuT $\mathrm{Au}_{4}$, Figure S3: Autocatalytic rate constants $k_{c}$ and the values of $\mathrm{m}$ and $\mathrm{n}$ for the aggregation of $\mathrm{TPPS}_{4} \mathrm{vs}$. [MnT $\mathrm{Mn}_{4}$, Figure S4: RLS intensity and extinction vs. $\left[\mathrm{MnT}_{4}\right]$, Figure S5: Autocatalytic rate constants $k_{c}$ and the values of $\mathrm{m}$ and $\mathrm{n}$ for the aggregation of $\mathrm{TPPS}_{4}$ as function of $\left[\mathrm{ZnT}_{4}\right.$ ], Figure S6: RLS intensity and extinction vs. [ZnT $\mathrm{Zn}_{4}$, Figure S7: UV/Vis extinction spectra of $\mathrm{TPPS}_{4} \mathrm{~J}$-aggregates in the presence of $\mathrm{AuT}_{4}, \mathrm{CoT}_{4}, \mathrm{ZnT}_{4}$ and $\mathrm{MnT}_{4}$, Table S1: Kinetic parameters for $\mathrm{TPPS}_{4}$ aggregation vs. $\left[\mathrm{MT}_{4}\right]$.

Author Contributions: Conceptualization, L.M.S., M.A.C. and A.R.; experiments, I.G.O., and R.Z.; formal analysis, M.T.; data curation, M.A.C.; writing—original draft preparation, L.M.S.; writing-review and editing, all Authors. All authors have read and agreed to the published version of the manuscript.

Funding: This research received no external funding.

Acknowledgments: The authors thank University of Messina and CNR for financial support.

Conflicts of Interest: The authors declare no conflict of interest.

\section{References}

1. Vantomme:, G.; Meijer, E.W. The construction of supramolecular systems. Science 2019, 363, $1396-1397$. [CrossRef] [PubMed]

2. Mattia, E.; Otto, S. Supramolecular systems chemistry. Nat. Nanotechnol. 2015, 10, 111-119. [CrossRef] [PubMed]

3. Alessio, E. Non-Covalent Multi-Porphyrin Assemblies Synthesis and Properties; Springer: Berlin/Heidelberg, Germany, 2006.

4. Magna, G.; Monti, D.; Di Natale, C.; Paolesse, R.; Stefanelli, M. The Assembly of Porphyrin Systems in Well-Defined Nanostructures: An Update. Molecules 2019, 24, 4307. [CrossRef] [PubMed]

5. Shee, N.K.; Kim, M.K.; Kim, H.-J. Supramolecular Porphyrin Nanostructures Based on Coordination-Driven Self-Assembly and Their Visible Light Catalytic Degradation of Methylene Blue Dye. Nanomaterials 2020, 10, 2314. [CrossRef] [PubMed]

6. Stefanelli, M.; Mandoj, F.; Magna, G.; Lettieri, R.; Venanzi, M.; Paolesse, R.; Monti, D. The Self-Aggregation of Porphyrins with Multiple Chiral Centers in Organic/Aqueous Media: The Case of Sugar- and SteroidPorphyrin Conjugates. Molecules 2020, 25, 4544. [CrossRef] [PubMed]

7. Abou-Gamra, Z.; Harriman, A.; Neta, P. Redox chemistry of gold(III) porphyrins in water. J. Chem. Soc. Far. Transact. 1986, 82, 2337-2350. [CrossRef]

8. Adler, A.D.; Longo, F.R.; Kampas, F.; Kim, J. On the preparation of metalloporphyrins. J. Inorg. Nucl. Chem. 1970, 32, 2443-2445. [CrossRef] 
9. Harriman, A.; Porter, G. Photochemistry of manganese porphyrins. Part 1.-Characterisation of some water soluble complexes. J. Chem. Soc. Far. Transact. 2 1979, 75, 1532-1542. [CrossRef]

10. Lin, M.; Marzilli, L.G. Solution Chemistry of Cobalt(III) Porphyrins in Water and Nonaqueous Solvents. Axial Ligation by Solvent and Counterion. Inorg. Chem. 1994, 33, 5309-5315. [CrossRef]

11. Monti, D.; Venanzi, M.; Stefanelli, M.; Sorrenti, A.; Mancini, G.; Di Natale, C.; Paolesse, R. Chiral Amplification of Chiral Porphyrin Derivatives by Templated Heteroaggregation. J. Am. Chem. Soc. 2007, 129, 6688-6689. [CrossRef]

12. Segawa,H.; Nishino, H.; Kamikawa, T.; Honda, K.; Shimidzu, T. Hetero-aggregation between Gold Porphyrins and Zinc Porphyrins through Charge Transfer Interaction. Chem. Lett. 1989, 18, 1917-1920. [CrossRef]

13. Mazur, U.; Hipps, K.W. A Systematic Approach toward Designing Functional Ionic Porphyrin Crystalline Materials. J. Phys. Chem. C 2018, 122, 22803-22820. [CrossRef]

14. Tian, Y.; Busani, T.; Uyeda, G.H.; Martin, K.E.; van Swol, F.; Medforth, C.J.; Montaño, G.A.; Shelnutt, J.A. Hierarchical cooperative binary ionic porphyrin nanocomposites. Chem. Commun. 2012, 48, 4863-4865. [CrossRef] [PubMed]

15. Medforth, C.J.; Wang, Z.; Martin, K.E.; Song, Y.; Jacobsen, J.L.; Shelnutt, J.A. Self-assembled porphyrin nanostructures. Chem. Commun. 2009, 47, 7261-7277. [CrossRef] [PubMed]

16. Tian, Y.; Martin, K.E.; Shelnutt, J.Y.T.; Evans, L.; Busani, T.; Miller, J.E.; Medforth, C.J.; Shelnutt, J.A. Morphological families of self-assembled porphyrin structures and their photosensitization of hydrogen generation. Chem. Commun. 2011, 47, 6069-6071. [CrossRef]

17. Shimidzu, T.; Iyoda, T. Accordion-type aggregate of water-soluble meso-tetraphenylporphyrin derivatives. Chem. Lett. 1981, 10, 853-856. [CrossRef]

18. Ojadi, E.; Selzer, R.; Linschitz, H. Properties of porphyrin dimers, formed by pairing cationic and anionic porphyrins. J. Am. Chem. Soc. 1985, 107, 7783-7784. [CrossRef]

19. Endisch, C.; Fuhrhop, J.-H.; Buschmann, J.; Luger, P.; Siggel, U. $\beta$-Tetraethyl- $\beta^{\prime}$-tetrapyridin-4-yl Porphyrins, Their N-Methylated Tetracations, and Heterodimers with ms-Tetraphenylsulfonato Porphyrins. J. Am. Chem. Soc. 1996, 118, 6671-6680. [CrossRef]

20. Schwab, A.D.; Smith, D.E.; Bond-Watts, B.; Johnston, D.E.; Hone, J.; Johnson, A.T.; de Paula, J.C.; Smith, W.F. Photoconductivity of Self-Assembled Porphyrin Nanorods. Nano Lett. 2004, 4, 1261-1265. [CrossRef]

21. Collini, E.; Ferrante, C.; Bozio, R.; Lodi, A.; Ponterini, G. Large third-order nonlinear optical response of porphyrin J-aggregates oriented in self-assembled thin films. J. Mater. Chem. 2006, 16, 1573-1578. [CrossRef]

22. Collini, E.; Ferrante, C.; Bozio, R. Strong Enhancement of the Two-Photon Absorption of Tetrakis(4sulfonatophenyl)porphyrin Diacid in Water upon Aggregation. J. Phys. Chem. B 2005, 109, 2-5. [CrossRef] [PubMed]

23. Kobayashi, T. J-Aggregates; World Scientific Publishing Company: Singapore, 1996; Volume 1.

24. Kobayashi, T. J-Aggregates; World Scientific Publishing Company: Singapore, 2012; Volume 2.

25. Micali, N.; Villari, V.; Castriciano, M.A.; Romeo, A.; Scolaro, L.M. From fractal to nanorod porphyrin J-aggregates. Concentration-induced tuning of the aggregate size. J. Phys. Chem. B 2006, 110, 8289-8295. [CrossRef] [PubMed]

26. Castriciano, M.A.; Romeo, A.; Villari, V.; Micali, N.; Scolaro, L.M. Nanosized porphyrin J-aggregates in water/AOT/decane microemulsions. J. Phys. Chem. B 2004, 108, 9054-9059. [CrossRef]

27. Castriciano, M.; Romeo, A.; Villari, V.; Micali, N.; Scolaro, L.M. Structural rearrangements in 5,10,15,20tetrakis(4-sulfonatophenyl)porphyrin J-aggregates under strongly acidic conditions. J. Phys. Chem. B 2003, 107, 8765-8771. [CrossRef]

28. Castriciano, M.A.; Leone, N.; Cardiano, P.; Manickam, S.; Scolaro, L.M.; Lo Schiavo, S. A new supramolecular polyhedral oligomeric silsesquioxanes (POSS)-porphyrin nanohybrid: Synthesis and spectroscopic characterization. Mater. Chem. C 2013, 1, 4746-4753. [CrossRef]

29. Castriciano, M.A.; Carbone, A.; Sacca, A.; Donato, M.G.; Micali, N.; Romeo, A.; De Luca, G.; Scolaro, L.M. Optical and sensing features of TPPS4 J-aggregates embedded in Nafion membranes: Influence of casting solvents. J. Mater. Chem. 2010, 20, 2882-2886. [CrossRef]

30. Castriciano, M.A.; Donato, M.G.; Villari, V.; Micali, N.; Romeo, A.; Scolaro, L.M. Surfactant-like Behavior of Short-Chain Alcohols in Porphyrin Aggregation. J. Phys. Chem. B 2009, 113, 11173-11178. [CrossRef] 
31. Lauceri, R.; Gurrieri, S.; Bellacchio, E.; Contino, A.; Scolaro, L.M.; Romeo, A.; Toscano, A.; Purrello, R. J-type aggregates of the anionic meso-tetrakis(4-sulfonatophenyl)porphine induced by 'hindered' cationic porphyrins. Supramol. Chem. 2000, 12, 193-202. [CrossRef]

32. Micali, N.; Romeo, A.; Lauceri, R.; Purrello, R.; Mallamace, F.; Scolaro, L.M. Fractal structures in homo- and heteroaggregated water soluble porphyrins. J. Phys. Chem. B 2000, 104, 9416-9420. [CrossRef]

33. Lauceri, R.; Fasciglione, G.F.; D'Urso, A.; Marini, S.; Purrello, R.; Coletta, M. Kinetic Investigation of Porphyrin Interaction with Chiral Templates Reveals Unexpected Features of the Induction and Self-Propagation Mechanism of Chiral Memory. J. Am. Chem. Soc. 2008, 130, 10476-10477. [CrossRef]

34. Mammana, A.; De Napoli, M.; Lauceri, R.; Purrello, R. Induction and memory of chirality in porphyrin hetero-aggregates: The role of the central metal ion. Biorg. Med. Chem. 2005, 13, 5159-5163. [CrossRef] [PubMed]

35. Wang, Z.; Medforth, C.J.; Shelnutt, J.A. Porphyrin Nanotubes by Ionic Self-Assembly. J. Am. Chem. Soc. 2004, 126, 15954-15955. [CrossRef] [PubMed]

36. Oztek, M.T.; Hampton, M.D.; Slattery, D.K.; Loucks, S. Hydrogen storage with hetero porphyrin aggregates. Int. J. Hydrogen Energy 2011, 36, 6705-6710. [CrossRef]

37. Di Natale, C.; Monti, D.; Paolesse, R. Chemical sensitivity of porphyrin assemblies. Mater. Today 2010, 13, 46-52. [CrossRef]

38. Purrello, R.; Scolaro, L.M.; Bellacchio, E.; Gurrieri, S.; Romeo, A. Chiral H- and J-Type Aggregates of meso-Tetrakis(4-sulfonatophenyl)porphine on a-Helical Polyglutamic Acid Induced by Cationic Porphyrins. Inorg. Chem. 1998, 37, 3647-3648. [CrossRef]

39. Purrello, R.; Raudino, A.; Scolaro, L.M.; Loisi, A.; Bellacchio, E.; Lauceri, R. Ternary porphyrin aggregates and their chiral memory. J. Phys. Chem. B 2000, 104, 10900-10908. [CrossRef]

40. Bellacchio, E.; Lauceri, R.; Gurrieri, S.; Scolaro, L.M.; Romeo, A.; Purrello, R. Template-imprinted chiral porphyrin aggregates. J. Am. Chem. Soc. 1998, 120, 12353-12354. [CrossRef]

41. Lauceri, R.; Raudino, A.; Scolaro, L.M.; Micali, N.; Purrello, R. From Achiral Porphyrins to Template-Imprinted Chiral Aggregates and Further. Self-Replication of Chiral Memory from Scratch. J. Am. Chem. Soc. 2002, 124, 894-895. [CrossRef]

42. Monsu Scolaro, L.; Castriciano, M.; Romeo, A.; Mazzaglia, A.; Mallamace, F.; Micali, N. Nucleation effects in the aggregation of water-soluble porphyrin aqueous solutions. Physica A 2002, 304, 158-169. [CrossRef]

43. Mallamace, F.; Monsu' Scolaro, L.; Romeo, A.; Micali, N. Crossover in the Kinetic Growth Process of Porphyrin Aggregation. Phys. Rev. Lett. 1999, 82, 3480-3483. [CrossRef]

44. Short, J.M.; Berriman, J.A.; Kubel, C.; El-Hachemi, Z.; Naubron, J.V.; Balaban, T.S. Electron Cryo-Microscopy of TPPS4 center dot 2HCl Tubes Reveals a Helical Organisation Explaining the Origin of their Chirality. Chem. Phys. Chem. 2013, 14, 3209-3214. [CrossRef] [PubMed]

45. Romeo, A.; Castriciano, M.A.; Zagami, R.; Pollicino, G.; Monsu Scolaro, L.; Pasternack, R.F. Effect of zinc cations on the kinetics for supramolecular assembling and the chirality of porphyrin J-aggregates. Chem. Sci. 2017, 8, 961-967. [CrossRef] [PubMed]

46. Occhiuto, I.G.; Zagami, R.; Trapani, M.; Bolzonello, L.; Romeo, A.; Castriciano, M.A.; Collini, E.; Monsu Scolaro, L. The role of counter-anions in the kinetics and chirality of porphyrin J-aggregates. Chem. Commun. 2016, 52, 11520-11523. [CrossRef] [PubMed]

47. Romeo, A.; Castriciano, M.A.; Occhiuto, I.; Zagami, R.; Pasternack, R.F.; Scolaro, L.M. Kinetic Control of Chirality in Porphyrin J-Aggregates. J.Am. Chem. Soc. 2014, 136, 40-43. [CrossRef] [PubMed]

48. El-Hachemi, Z.; Escudero, C.; Acosta-Reyes, F.; Casas, M.T.; Altoe, V.; Aloni, S.; Oncins, G.; Sorrenti, A.; Crusats, J.; Campos, J.L.; et al. Structure vs. properties-Chirality, optics and shapes-in amphiphilic porphyrin J-aggregates. J. Mater. Chem. C 2013, 1, 3337-3346. [CrossRef]

49. Kalyanasundaram, K. Photochemistry of water-soluble porphyrins: Comparative study of isomeric tetrapyridyl- and tetrakis(N-methylpyridiniumyl)porphyrins. Inorg. Chem. 1984, 32, 2453-2459. [CrossRef]

50. Pasternack, R.F.; Fleming, C.; Herring, S.; Collings, P.J.; de Paula, J.; DeCastro, G.; Gibbs, E.J. Aggregation kinetics of extended porphyrin and cyanine dye assemblies. Biophys. J. 2000, 79, 550-560. [CrossRef]

51. Pasternack, R.F.; Gibbs, E.J.; Collings, P.J.; de Paula, J.C.; Turzo, L.C.; Terracina, A. A nonconventional approach to supramolecular formation dynamics. The kinetics of assembly of DNA-bound porphyrins. J. Am. Chem. Soc. 1998, 120, 5873-5878. [CrossRef] 
52. Occhiuto, I.G.; Castriciano, M.A.; Trapani, M.; Zagami, R.; Romeo, A.; Pasternack, R.F.; Monsù Scolaro, L. Controlling J-Aggregates Formation and Chirality Induction through Demetallation of a Zinc(II) Water Soluble Porphyrin. Intern. J. Mol. Sci. 2020, 21, 4001. [CrossRef]

53. Zagami, R.; Romeo, A.; Castriciano, M.A.; Monsù Scolaro, L. Inverse Kinetic and Equilibrium Isotope Effects on Self-Assembly and Supramolecular Chirality of Porphyrin J-Aggregates. Chem. Eur. J. 2017, 23, 70-74. [CrossRef]

54. Castriciano, M.A.; Romeo, A.; Zagami, R.; Micali, N.; Scolaro, L.M. Kinetic effects of tartaric acid on the growth of chiral J-aggregates of tetrakis(4-sulfonatophenyl)porphyrin. Chem. Commun. 2012, 48, 4872-4874. [CrossRef] [PubMed]

55. Parkash, J.; Robblee, J.H.; Agnew, J.; Gibbs, E.; Collings, P.; Pasternack, R.F.; de Paula, J.C. Depolarized resonance light scattering by porphyrin and chlorophyll a aggregates. Biophys. J. 1998, 74, 2089-2099. [CrossRef]

56. Pasternack, R.F.; Collings, P.J. Resonance Light-Scattering-A New Technique for Studying Chromophore Aggregation. Science 1995, 269, 935-939. [CrossRef] [PubMed]

57. Frenkel, J. On the Transformation of light into Heat in Solids. I. Phys. Rev. 1931, 37, 17-44. [CrossRef]

Sample Availability: Samples of the investigated J-aggregates are available from the authors.

Publisher's Note: MDPI stays neutral with regard to jurisdictional claims in published maps and institutional affiliations.

(C) 2020 by the authors. Licensee MDPI, Basel, Switzerland. This article is an open access article distributed under the terms and conditions of the Creative Commons Attribution (CC BY) license (http://creativecommons.org/licenses/by/4.0/). 